\title{
O LUGAR DA EDUCAÇÃO PROFISSIONAL NA GARANTIA DO DIREITO
}

\author{
Nívia Barreto dos Anjos* \\ *E-mail: nivia.barreto@ifbaiano.edu.br \\ Instituto Federal de Educação, Ciência e Tecnologia Baiano, Campus Santa Inês, Brasil
}

DOI: $10.15628 /$ rbept.2020.8766

Artigo submetido em jun/2019 e aceito em dez/2019

\section{RESUMO}

Este artigo retrata sobre o Lugar da educação profissional na garantia do direito. O objetivo geral consiste em discutir o lugar da educação profissional na garantia do direito, visando compreender o quanto ela pode impactar a vida acadêmica de estudantes em situação de vulnerabilidade social. O problema de investigação levantado consiste em verificar se apesar de toda investida do capital financeiro à educação profissional ainda é possível ofertar um ensino de qualidade socialmente referenciado? A relevância do estudo realizado está em perceber que educação profissional que foi criada para os pobres, mas que nunca se permitiu ser pobre precisa resistir com a mesma qualidade, principalmente nos tempos atuais - de ataques à educação.

Palavras-Chave: Educação Profissional. Institutos Federais. Capitalismo Financeiro. Lei de Diretrizes e Bases da Educação Nacional.

\section{THE PLACE OF PROFESSIONAL EDUCATION IN GUARANTEE OF LAW}

\begin{abstract}
This article portrays the Place of Vocational Education in Securing the Right. The general objective is to discuss the place of professional education in guaranteeing the right, aiming to understand how it can impact the academic life of students in poverty. The research problem raised is to verify whether despite all the financial capital invested in vocational education it is still possible to offer a socially referenced quality education? The relevance of the study is to realize that vocational education that was created for the poor but never allowed to be poor must resist with the same quality, especially in modern times - attacks on education.
\end{abstract}

Keywords: Professional education. Federal Institutes. Financial capitalism. Law of National Education Guidelines and Bases. 


\section{INTRODUÇÃO}

É preciso atuar em meio às contradições do modelo hegemônico vigente no sentido de produzir movimentos que contribuam para o rompimento da dualidade educacional, o que também contribuirá para a superação do sistema capital.

Dante Moura (2003, p. 719).

Percebe-se, nos tempos atuais, que a educação é alvo de ataque do capital financeiro, exatamente por ameaçar sua hegemonia, podendo gerar uma contra-hegemomia. $E$ no que se refere à educação profissional, a situação é ainda mais agravante, visto que ela é alvo deste desmonte implantado de forma mais intensa.

O capital por meio de seus porta vozes, especialmente os Governos Temer e Bolsonaro, procura intensificar uma concepção de que a educação profissional é muito dispendiosa devido a qualidade do ensino que ela proporciona. Por isso em meio a tamanha "balburdia" é preciso parafrasear Dante Moura (2013) e acreditar que quem vai plantar e cuidar para que cresçam as sementes da educação profissional de qualidade - aproveitandose das contradições do sistema capitalista - são os movimentos sociais da educação.

E esses movimentos, especialmente os dos estudantes, procuram demonstrar que não fazem "balburdia" nos Institutos Federais, mas que almejam plantar e cuidar para garantir o lugar da educação profissional na sociedade comandada pelo capital.

Em 2019, o Campus Bom Jesus da Lapa do IF Baiano organizou um documentário com interessantes depoimentos dos estudantes:

O governo não investe na educação porque a educação pode derrubar o governo, eu não estou aqui para fazer balbúrdia; Sr Presidente, eu não venho para o IF fazer balburdia, eu tô aqui na escola para fazer ciência, educação e tecnologia; venho em busca de um ensino melhor, não estou aqui para fazer balburdia (Documentário Tira a Mão do Meu IF: Campus Bom Jesus da Lapa, 2019)

Lembrando sempre que tanto a Educação quanto a Educação Profissional são campos de disputa e de negociação, nos quais ocorrem verdadeiras investidas do Capital. $\mathrm{E}$ neste árduo caminho congestionado pelas mazelas do capital, a luta e a resistência dos movimentos sociais da educação que procuram plantar e cuidar deste direito pode representar uma grande diferença na garantia do lugar da educação profissional na sociedade capitalista. 


\title{
2 DESENVOLVIMENTO
}

De início será retratado o lugar da educação profissional na sociedade capitalista lembrando do seu histórico de ter sido criada para os pobres, mas de jamais ter se permitido ser pobre. Em seguida será abordado o lugar da educação profissional da Lei de Diretrizes e Bases da Educação Nacional com destaque para o pensamento de Dante Moura sobre o espaço contraditório em que ela se insere. Por fim, será destacado o lugar dos institutos federais em tempos de "Santíssima trindade do Capital", lembrando que o direito à educação tem sido alvo de ataques, sendo diretamente penalizado por uma política de desmantelamento das políticas sociais que foram garantidas pela Constituição de 1988.

\subsection{O LUGAR DA EDUCAÇÃO PROFISSIONAL NA SOCIEDADE CAPITALISTA}

A educação tem um lugar determinante na sociedade dominada pelo capital e a educação profissional também, sendo assim a luta pela sua permanência com qualidade socialmente referenciada deve ser intensificada.

Os estudos de Gramsci ressaltaram também a educação profissional. De acordo com Gruppi (1978), Gramsci "indica, na divisão entre escola profissional e escola ginasial-colegial, a fratura típica, da escola italiana: a escola profissional para os que vão trabalhar em posições subalternas e o ginásio-colégio para os quadros dirigentes da sociedade." (p. 68) e isto reflete na atualidade os impactos sofridos pela educação profissional.

Manfredi (2002) comenta que os paradigmas que dão suporte a educação profissional foram construídos historicamente e no presente acabam por serem ressignificados.

\begin{abstract}
Assim, entre as diversas concepções, há desde as que consideram a Educação Profissional numa perspectiva compensatória e assistencialista, como uma forma de educação para os pobres, até aquelas centradas na racionalidade técnico-instrumental, as quais postulam uma formação voltada para a satisfação das mudanças e inovações do sistema produtivo e dos ditames do atual modelo econômico de desenvolvimento brasileiro, além de outras orientadas pela ideia de uma educação tecnológica, numa perspectiva de formação de trabalhadores como sujeitos coletivos e históricos. (MANFREDI, 2002, p. 57)
\end{abstract}

Moura (2007) ao fazer uma retrospectiva histórica de educação profissional afirma que ela foi fruto de uma dualidade, visto que a educação básica que possuía um caráter mais propedêutico foi direcionada para as elites, enquanto que a educação profissional foi criada para os filhos das classes populares.

A Educação Profissional teve seus primórdios legais com a oficialização no Brasil do Decreto n. 7566, de 23 de setembro de 1909, no 
governo Nilo Peçanha, quando foram criadas em todas as capitais as Escolas de Aprendizes e Artífices, como pode ser constatado na citação deste Decreto a seguir:

O aumento constante da população das cidades exigia que se facilitasse às classes proletárias os meios de vencer as dificuldades sempre crescentes na luta pela existência e que, para isso, se tornava necessário, não só habilitar os filhos dos desfavorecidos da fortuna com o indispensável preparo técnico e intelectual, como fazê-los adquirir hábitos de trabalho profícuo que os afastassem da ociosidade, da escola do vício e do crime. (ROSSETI JUNIOR, 2018, p. 10)

Por meio deste Decreto Presidencial fica claro que no Brasil, a educação tecnológica surgiu como meio de promover o acesso ao mercado de trabalho de pessoas provenientes de famílias em situação de vulnerabilidade, como também de enfrentar a ociosidade destes cidadãos.

A educação profissional no Brasil tem, portanto, a sua origem dentro de uma perspectiva assistencialista com o objetivo de "amparar os órfãos e os demais desvalidos da sorte", ou seja, de atender àqueles que não tinham condições sociais satisfatórias, para que não continuassem a praticar ações que estavam na contra ordem dos bons costumes. (MOURA, 2007, p. 6)

De acordo com Pereira, (2018) sabe-se que a formação para o trabalho nas primeiras décadas do Brasil republicano foi expediente usado pela classe dirigente como meio de contenção da desordem social, sinais de um período de transição, marcado pelo processo de urbanização, com notável mobilização popular e classista por melhores condições de vida e de trabalho. Foi neste cenário que o presidente Nilo Peçanha, por meio do Decreto 7566, criou uma rede de Escolas de Aprendizes Artífices, cuja missão primeira seria prover as classes proletárias de meios que garantissem a sua sobrevivência.

Rossetti Junior (2018) refere-se a este Decreto enfatizando que o objetivo precípuo das Escolas de Aprendizes e Artífices era habilitar os filhos dos desfavorecidos da fortuna com indispensável preparo técnico e intelectual. Acrescenta ainda que a frase dita pelo Presidente Nilo Peçanha marcou essa ação governamental: "O Brasil de ontem saiu das academias, o de amanhã sairá das oficinas" (ROSSETI JUNIOR, 2018, p. 07)). Ou seja, essa rede era criada para atender aos "desvalidos da sorte", jovens oriundos das camadas populares da sociedade.

Amâncio Filho (2018), assim como Moura, afirma que o surgimento das escolas técnicas com o objetivo de ensinar algum ofício àqueles 'desfavorecidos da fortuna', estabeleceu uma forte divisão entre o ensino técnico e o ensino propedêutico, o primeiro com caráter de terminalidade, destinado aos segmentos populacionais mais pobres e, o segundo, reservado para os filhos das classes sociais mais abastadas, servindo como preparação para o ingresso na universidade. 
Moura (2007) explica que em 1910 foi organizado o ensino agrícola com objetivo na época de capacitar capatazes, administradores e chefes de cultura.

A criação das Escolas de Aprendizes Artífices e do ensino agrícola evidenciou um grande passo ao redirecionamento da educação profissional no país, pois ampliou o seu horizonte de atuação para atender necessidades emergentes dos empreendimentos nos campos da agricultura e da indústria. (MOURA, 2007, p. 7).

Segundo Leite (2001) a 1a fase da educação tecnológica ocorreu entre a sua implantação em 1909 até 1946. Com o surgimento do Estado Novo e o início do processo de industrialização no Brasil surgiu uma $2^{\underline{a}}$ fase vivenciada pela educação profissional.

Ainda conforme Leite (2001) foi necessário criar uma nova estratégia de desenvolvimento, pois três desafios deveriam ser atingidos: 1. Falta de um empresariado com perfil moderno; 2. Baixa qualificação de recursos humanos; 3. Insuficiente mercado de consumo interno.

Diante deste quadro, foi preciso que o Estado assumisse o papel de condutor do processo de desenvolvimento, expandindo-se e fortalecendo-se para dar início ao processo de industrialização. Neste período, as Escolas de Aprendizes Artífices sofreram mudança de nomenclatura para Liceu Industrial e, posteriormente, para Escola Técnica.

Leite (2001) salienta que, impulsionada pelas demandas do capitalismo, surgiu a partir de 1970, uma $3^{\underline{a}}$ fase da educação profissional, pois a estratégia de substituição das importações havia começado a dar sinais de esgotamento. Neste período iniciou-se a expansão do capitalismo internacional.

A civilização do capital interligou o mundo, criando em todos os pontos do globo idênticas vontades e necessidades, iniciativas e impasses, soluções e problemas, semelhante tecido social. Converteu toda riqueza em riqueza industrial; todo trabalho em trabalho morto a serviço do capital...Ao longo desse percurso - que ainda não se consumou -, teve o capital que dissolver tudo que é sólido, redefinindo, destruindo e / ou recriando, a cada tempo e lugar, segundo seus interesses conjunturais e exigências estruturais, o papel de todas e de cada uma dessas formatações societárias. (MELLO, 1998, p. 31)

Com essas três fases, é possível constatar que a educação profissional vivenciou e vivencia um eterno conflito, o de oferecer formação tecnológica com qualidade, mesmo estando moldada por um capitalismo selvagem.

Convém destacar que, no decorrer da história da educação profissional no país, o perfil social dos alunos foi sendo modificado, como reflexo do processo de industrialização, e consequentemente, da perda do poder de compra da classe média brasileira. As Escolas Técnicas foram se elitizando e consequentemente, excluindo os alunos de baixa renda. Amâncio Filho (2018) chega a afirmar que o que se observa hoje é um aumento da procura 
de vagas no ensino técnico por candidatos oriundos das classes média e média alta, provocando mudança no perfil do alunado.

Todavia, com a Política de Cotas implantada no Brasil da década de 2010 a população em situação de vulnerabilidade social voltou a adentrar os Institutos Federais de Educação, inclusive no IF Baiano a cota para estudantes oriundos das escolas públicas é de $70 \%$.

\subsection{O LUGAR DA EDUCAÇÃO PROFISSIONAL NA LDB}

Moura (2007) ainda salienta que o período que antecedeu a promulgação da primeira Lei de Diretrizes e Bases da Educação - LDB que só entrou em vigor em 1961, foi cheio de discussões e debates a respeito da sociedade brasileira que se encontrava em conflito entre modelos distintos de desenvolvimento. Após a Segunda Guerra Mundial, retorna a dependência às economias hegemônicas mundiais, porém "a aceleração da diversificação industrial continua gerando o Estado desenvolvimentista-populista sustentado na aliança entre o empresariado, desejoso de expansão, e setores populares com aspirações de maior participação econômica e política". (MOURA, 2007, p. 10).

Especificamente na esfera educacional, a principal polêmica continuou sendo o conflito entre os que advogam por uma educação pública, gratuita, laica e de qualidade para todos, independente da origem socioeconômica, étnica, racial etc. e os defensores da submissão dos direitos sociais em geral e, particularmente, da educação à lógica da prestação de serviços sob a argumentação da necessidade de diminuir o estado que gasta muito e não faz nada bem feito. (MOURA, 2007, p. 14 e 15).

Neste sentido, Frigotto (2001) chega a afirmar que projeto societário e educativo apresentado pelo capital consiste em tornar a educação como um todo, e, em especial a educação profissional, vinculada a uma perspectiva de adestramento e acomodação, procurando promover o cidadão a uma simples pessoa empregável e disponível para o mercado de trabalho.

Demo (1997) registra que a nova LDB não é inovadora em relação aos desafios modernos enfrentados pela educação. Traz novos componentes, porém continua predominando a visão tradicional.

A Lei reflete, aí, nada mais do que a letargia nacional nesse campo, que impede de perceber o quanto as oportunidades de desenvolvimento dependem da qualidade educativa da população. É difícil fugir da constatação de que para a elite interessa, pelo menos em certa medida, a ignorância da população, como tática para manutenção do status quo. Essa percepção torna-se tanto mais complicada, porque para uma parte da elite já não poderia interessar o atraso, porque este não lhe dá mais lucro. A competitividade moderna da economia está intrinsicamente conectada com a questão educativa, ainda que se fixe no trabalhador. Entretanto, mesmo assim, pode-se afirmar hoje que um trabalhador que 
não sabe pensar já não é útil para a produtividade moderna. (DEMO, 1997, p.67)

Moura (2007) chega a afirmar que a estrutura da nova LDB está dividida em dois níveis: educação básica e educação superior; e por incrível que pareça a educação profissional não se encontra em nenhum dos dois níveis, o que consolida a dualidade histórica de forma completamente clara. Para ele, a educação profissional não faz parte da educação regular brasileira, pois é tida como algo que vem paralelo, como um verdadeiro apêndice apelidado de modalidade.

Por outro lado, a nova LDB, segundo Saviani (2011) traz no capítulo III, do Título $\mathrm{V}$, artigos nos quais se estabelece a integração da educação profissional com as diferentes formas de educação, com o trabalho, com a ciência e a tecnologia (art 39). Isto porque segundo Ciavatta (2005) "a formação integrada sugere tornar integro, inteiro, o ser humano dividido pela divisão social do trabalho entre a ação de executar e a ação de pensar, dirigir ou planejar" (CIAVATTA, 2005, p. 2), buscando-se garantir o direito a uma formação que faça uma leitura do mundo e a compreensão das relações sociais.

Souza (2017) afirma que apesar da LDB destinar um capítulo específico para a educação profissional, este é ainda muito sucinto e sua regulamentação só ocorreu em 1997, por meio de Decreto n. 2208, que acabou sendo revogado em 2004, através do Decreto n. 5154, o qual representou o aparato jurídico para a Reforma da Educação Profissional. E Moura (2007) lembra que durante o ano de 2003 e até julho de 2004 ocorreram muitos intensificados debates relativos à relação entre ensino médio e a Educação Profissional.

Esse instrumento legal, além de manter as ofertas dos cursos técnicos concomitantes e subsequentes trazidas pelo Decreto n. 2208/97, teve o grande mérito de revoga-lo e de trazer de volta a possibilidade de integrar o ensino médio a educação profissional técnica de nível médio, agora, numa perspectiva que não se confunde com a educação tecnológica ou politécnica, mas que aponta em sua direção porque contém os princípios da sua construção (MOURA, 2007, p. 20)

O Plano Nacional de Educação de 2001 (Brasil 2001) afirma que a maior dificuldade em relação a educação profissional refere-se a alta qualidade do ensino que ela oferece que está associado a um custo extremamente elevado para sua manutenção, o que acaba gerando um número limitado de vagas.

Entre as diretrizes deste PNE, destacam-se;

12. Reorganizar a rede de escolas agrotécnicas, de forma a garantir que cumpram o papel de oferecer educação profissional específica e permanente para a população rural, levando em conta seu nível de escolarização e as peculiaridades e potencialidades da atividade agrícola na região; 13. Estabelecer junto às escolas agrotécnicas e emcolaboração com o Ministério da Agricultura cursos básicos para agricultores, voltados para a melhoria do nível 
técnico das práticas agrícolas e da preservação ambiental, dentro da perspectiva de desenvolvimento auto-sustentável. (BRASIL, 2001, p. 51).

E o PNE 2014-2024 apresenta na Meta 11 a necessidade de "triplicar as matrículas da educação profissional técnica de nível médio, assegurando a qualidade da oferta e pelo menos cinquenta por cento da expansão no segmento público" (BRASIL, 2014, p. 71).

E a estratégia para esta meta consiste em:

\begin{abstract}
11.1 expandir as matrículas de educação profissional técnica de nível médio na rede Federal de Educação Profissional, Científica e Tecnológica, levando em consideração a responsabilidade dos institutos na ordenação territorial, sua vinculação com arranjos produtivos, sociais e culturais locais e regionais, bem como a interiorização da educação profissional (BRASIL, 2014, p. 71).
\end{abstract}

Araújo e Rodrigues (2010) registram que a educação, inclusive a profissional, fazem parte de campos de disputa nos quais prevalecem dois tipos de abordagem: 1) os que buscam a conformação dos homens à realidade dada; 2) Os que procuram a transformação social. "Tais abordagens consubstanciam em nossa sociedade, dois projetos antitéticos de formação dos trabalhadores: uma pedagogia focada no trabalho e outra pedagogia focada no capital" (IDEM, 2010, p. 51).

Os autores salientam que é necessário um projeto democrático de educação profissional que assuma uma nova postura frente aos saberes, às práticas de ensinar e de aprender, aos procedimentos de organização curricular e de avaliação. E a construção dessa educação profissional qualitativamente nova perpassa pela sua emancipação em relação ao controle do capital.

\title{
2.3 O LUGAR DOS INSTITUTOS FEDERAIS EM TEMPOS DE "SANTÍSSIMA TRINDADE DO CAPITAL"
}

Em 2008, por meio da Lei n. 11.892, foram criados os Institutos Federais de Educação, Ciência e Tecnologia. E Moura (2007) ressalta que "uma possibilidade para os filhos da classe trabalhadora é a tentativa de ingresso em uma das instituições que compõem a Rede Federal de Educação Profissional, instituições que historicamente atuam como referência nos vários componentes que constituem a formação integral" (MOURA, 2007, p. 21). Mas Moura ainda lembra que a concorrência para ingresso na Educação Profissional é muito grande, visto que o número de vagas é limitado.

Percebe-se que todo histórico que envolve a educação profissional é imbuído de avanços e retrocessos, e que se encontra presente a necessidade de luta social intensificada para que ela seja concebida como um direito e não como um apêndice/modalidade, principalmente pela qualidade de ensino que ela oferece. 
O direito à educação tem sido alvo de ataques, sendo diretamente penalizado por uma política de desmantelamento das políticas sociais que foram garantidas pela Constituição de 1988. Mas o povo brasileiro precisa se mobilizar para que essas agressões a esse direito que tem uma caminhada histórica tão linda sejam barradas e os movimentos sociais da educação possuem competência técnica para levantar a bandeira da educação profissional e enfrentar a voracidade do capital contra a educação.

lamamoto (2008) comenta que na esfera das finanças o capital aparece como possível criador de "ovos de ouro", e que os principais representantes das classes dominantes no mundo globalizado são: o Fundo Monetário Internacional, o Banco Mundial e a Organização Mundial do Comércio, que a autora classifica como a "santíssima trindade do capital".

Torna-se então imprescindível trazer a discussão sobre "A Nova Investida do Banco Mundial por meio de artigo escrito por Graça Druck, Luiz Filgueiras e Uallace Moreira, o qual foi publicado no caderno do Centro de Estudos e Ação Social (CEAS) em 2017.

Essa nova ofensiva do neoliberalismo, contra as Universidades Públicas Brasileiras, vocaliza e traz, subjacente a ela, os interesses do capital financeiro e dessas grandes corporações internacionais e, também, de grandes grupos privados nacionais que investem no ensino superior. (DRUCK, FIGUEIRAS E MOREIRA, 2017, p. 605)

Os autores explicam que atualmente a educação superior no Brasil é um grande negócio e por incrível que pareça "o Estado financiou, a juros subsidiados, a implantação e/ou ampliação das instalações físicas (capital fixo) dos grandes grupos econômicos privados" (p. 620). Sendo as maiores instituições privadas de Ensino Superior do país: Anhanguerra Educacional, Estácio Participações e a Kroton.

Os recursos do FIES e do PROUNI são transferidos diretamente para as corporações do ensino superior, a inadimplência dos estudantes "beneficiados" é zero e os valores cobrados pelas matrículas e mensalidades exorbitantes - principalmente nas chamadas "ciências duras". Esse é o "liberalismo" e o "menos Estado" do Bird, do capital financeiro e da direita liberal brasileira; na verdade, sem a transferência de recursos públicos (orçamentários), agora também para grandes grupos internacionais, esse negócio não poderia sobreviver, pelo menos na enorme dimensão que assumiu no Brasil. (DRUCK, FIGUEIRAS E MOREIRA, 2017, p. 605).

Para os três estudiosos existe uma tendência por parte do Bird de desvalorizar as universidades públicas como ineficientes e de fomentar um ataque político - ideológico de desqualificação aos servidores públicos. Por outro lado, verifica-se que, de acordo com os indicadores do Tesouro Nacional, se entre 2000 a 2015, os gastos com educação não ultrapassaram a 3,6, já com a Dívida Interna e Externa chegaram ao percentual 70,5 do orçamento da União. 
Com relação às receitas, é conhecida a estrutura tributária vergonhosamente regressiva existente no Brasil, calcada, sobretudo, em impostos indiretos que sobrecarregam as famílias de baixa renda, enquanto não se tributam os ganhos financeiros, a propriedade fundiária e a herança [...] Para complementar, é reconhecida a existência de uma enorme evasão fiscal, ocorrida através da sonegação, da sistemática renúncia fiscal para os grandes grupos econômicos e de sucessivos e reiterados perdões aos sonegadores (REFIS) (IDEM, p. 608 e 609).

É nesse sentido que Fagnani (2017) chega a afirmar que "O 'Novo Regime Fiscal' ultrapassa a mera questão do ajuste fiscal. O que está em curso é o rompimento em relação ao modelo de sociedade pactuado em 1988" (p. 14). Isto porque "o Brasil é uma das sociedades mais desiguais do mundo e o sistema tributário contribui para ampliar essas desigualdades". (p. 16).

Por isso Manfrendi (2002) relembra que o sistema de educação de uma sociedade "é produto de um complexo movimento de construção/reconstrução, determinado por fatores de ordem econômico-social e político cultural" (p. 32). Esses fatores vão definir o contexto em que irão atuar os diferentes protagonistas sociais, com interesses muitas vezes opostos.

Percebe-se que a ameaça do capital financeiro à educação superior e à educação profissional tem se intensificado nos últimos anos, com investida violenta contra os Institutos Federais. Neste sentido, é preciso estar atento que apesar de todo ataque existente "A educação profissional é um campo de disputa e de negociação entre os diferentes segmentos e grupos que compõem uma sociedade..."(MANFREDI: 2002, p. 61)

Os processos de participação política abriram brechas, possibilidades de disputa de hegemonia, tanto no interior do próprio aparelho de Estado como no âmbito da sociedade civil. Tais disputas favorecem a constituição de mecanismos de representação, de negociação e de elaboração de estratégias de ação, empurrando a oferta da educação e seu consumo para além das necessidades do sistema produtivo. (IDEM, 2002, p. 59).

Isto porque para a autora os espaços da política tornam-se palco de lutas pela ampliação e melhoria da qualidade da educação, distanciando-a da perspectiva dos grupos hegemônicos. Assim, a escola extrapola a função determinada pelo capital financeiro de ser instrumento de certificação e credenciamento para a manutenção no mercado de trabalho e passa a ser um espaço de inserção político-social e cultural.

É importante lembrar que de acordo com Dal Ri e Vietitez (2009) o neoliberalismo ao se expressar globalmente de forma político-econômica, acaba cometendo graves falhas, gerando desequilíbrios regionais, enfraquecendo os eixos do sistema mercantil-financeiro, ampliando as desigualdades entre as classes sociais, e afetando seriamente a devastação da própria natureza. Provocando o crescimento da miséria e da pobreza em todo o mundo. 
Consciente do lugar da escola na sociedade capitalista, Ramos (2018) registra que a escola possui uma relação histórica com o mundo da produção, por isso, a cada nova fase da produção humana, da ciência e da tecnologia aparecem novas alternativas e exigências educativas vão se manifestando.

Por isso Ramos (2018) afirma que

A rede de Instituições Federais de Educação Profissional e Tecnológica cumpriu com a finalidade manifesta e tencionou a contradição em benefício do trabalho. Isso quer dizer que os cursos técnicos de segundo grau, ofertados por essas instituições, reuniram formação geral e profissional, com instalações de qualidade, professores bem formados e condições de trabalho[...] Ihes conferiam não somente uma formação de qualidade, mas uma compreensão do mundo mais ampliada. (p. 27 e 28)

Isto porque segundo a autora "no ensino, é preciso que os conteúdos sejam apreendidos como um sistema de relações que expressam a totalidade social" (RAMOS: 2018, p. 35) . Mas, a atual contrarreforma da educação quer destruir tudo que foi conquistado até o momento. Para Ramos (2018), "a contrarreforma atual é a expressão da hegemonia do pensamento burguês, conservador e retrógrafo..."(p. 37) .

Mas a pesquisadora lembra que "as ideias hegemônicas são aquelas que dão direção cultural e material a um grupo. Ela se disputa e se conquista numa sociedade que tem relações, formalmente, consideradas democráticas..." (RAMOS: 2018, p. 37) . E já que o Brasil não vive na atualidade um estado ditatorial, no qual predomina a coerção, o consenso das massas é imprescindível; por isso apesar de todo o desmonte que a burguesia tem provocado na educação e em especial na educação profissional, tendo como princípio uma contrarreforma que quer oferecer uma "educação mínima, para cidadãos mínimos" (p. 40), "as lutas se travam nos planos econômico e político, mas também filosófico" (p.42).

A atual contrarreforma do Ensino Médio é mais um componente do movimento austericida liderado pelos que estão no poder e por aqueles que buscam o consenso da sociedade civil por artifícios midiáticos e ideológicos, coordenado pelo "novo regime fiscal"[...] Vivemos, no plano educacional, a violência e o ferimento da morte de um projeto de formação humana voltada para a construção de outra sociedade. Volta-se ao século XIX, quando a classe trabalhadora deveria receber educação somente em doses homeopáticas (RAMOS: 2018, p. 42)

Seguindo este pensamento, Dal Ri e Vieitez (2009) esclarecem que o trabalho e o ensino para o pensamento hegemônico é relevante como uma forma de qualificar, capacitar os homens para as novas exigências do mercado de trabalho, aumentar a produtividade e criar riquezas. Paralelamente, é uma forma de disciplinar e treinar os trabalhadores para que se adaptem a hierarquia e à divisão do trabalho. Já para o grupo contrahegemônico, o trabalho é um princípio educativo que proporciona aos homens enquanto sujeitos uma formação integral. 
E de forma impactante, Moura (2013) afirma "que é possível, e necessário, plantar e cuidar para que cresçam as sementes da formação humana integral, aproveitando-se das contradições do sistema capital." (p. 713)

Marx, no capítulo XIII de O Capital, ao se referir à legislação fabril inglesa, esclarece que na luta pela conquista do poder há fases intermediárias que vão se engendrando na medida em que as posições relativas das classes em conflito se alteram de acordo com a correlação de forças entre elas. (MOURA: 2013, p. 209).

Então, o que está em jogo é a intensidade da correlação de forças, visto que é bem nítido o desmonte que o capital financeiro tenta impor sobre a educação, e Druck, Filgueira e Moreira (2017) retratam isto de forma clara:

\begin{abstract}
Não pode haver ilusão; o papel do ajuste fiscal não é "sanear" as finanças públicas, como foi no passado, quando o padrão de desenvolvimento era hegemonizado pelo capital industrial. Este tipo de política não tem mais essa função nem capacidade, o seu papel é garantir a transferência permanente de recursos públicos e de renda das atividades produtivas para a especulação financeira, da população em geral para os maisricos[...] O ajuste fiscal tem, claramente, um caráter de classe: é uma escolha a favor do capital, em especial do capital financeiro, e dos mais ricos; e contra os trabalhadores, em especial seus segmentos mais fragilizados. (p. 613)
\end{abstract}

Reflexo disto é a proposta apresentada recentemente de redimensionamento dos Institutos Federais no Brasil que expressa claramente os interesses da "santíssima trindade do capital". Ela vem de cima para baixo e aparece como uma imposição. Mas os movimentos sociais pela educação e os estudiosos da educação profissional estão aí para enfrentar os ditames do capital financeiro, com pesquisas e campanhas de resistência.

\title{
3 METODOLOGIA
}

O objetivo geral deste artigo consiste em discutir o lugar da educação profissional na garantia do direito, visando compreender o quanto ela pode impactar a vida acadêmica de estudantes em situação de vulnerabilidade social. E específicos: - Entender o lugar da educação professional na sociedade capitalista; -compreender o o lugar da educação professional da Lei de Diretrizes e Bases Nacional; - pensar sobre o lugar dos Institutos Federais em tempos de dominação da "Santissima Trindade do Capital".

O problema de investigação levantado consiste em verificar se apesar de toda investida do capital financeiro à educação profissional ainda é possível ofertar um ensino de qualidade socialmente referenciado?. E a resposta é que sim, mas as lutas são grandes e os enfrentamentos necessários e devem ocorrer com muita resistência e coerência técnica e teórica. 
A relevância do estudo realizado neste artigo está em perceber que educação profissional que foi criada para os pobres mas que nunca se permitiu ser pobre precisa resistir com a mesma qualidade, principalmente nos tempos atuais - de ataques à educação .

Sendo assim, faz-se a opção neste artigo pela adoção de uma metodologia dinâmica e que abranja o método investigativo, os procedimentos e as técnicas que devem ser adotadas pelo pesquisador nesta orientação. Assim, foi possível recorrer a uma metodologia que traçasse o caminho a ser permeado de forma crítica e criativa, isto porque de acordo com Minayo,

A metodologia inclui as concepções teóricas de abordagem, o conjunto de técnicas que possibilitam a construção da realidade e o sopro divino do potencial criativo do investigador[...] A pesquisa é um labor artesanal, que se não prescinde da criatividade, se realiza fundamentalmente por uma linguagem fundada em conceitos, proposições, métodos e técnicas, linguagem esta que se constrói com um ritmo próprio e particular. A esse ritmo denominamos ciclo da pesquisa, ou seja, um processo de trabalho em espiral que começa com um problema ou uma pergunta e termina com um produto provisório capaz de dar origem a novas interrogações. (MINAYO, 2004, p. 16, 25-26)

Dentro deste artigo, o sopro divino do potencial criativo descrito por Minayo levou a autora a realização de uma pesquisa bibliográfica envolvendo três categorias e sua relação com a educação profissional: Sociedade Capitalista, Lei de Diretrizes e Bases da Educação Nacional, e "Santíssima Trindade do Capital.

Conforme Triviños (1987) a seleção do material bibliográfico que o pesquisador tem acesso possibilitará analisar até onde outros estudiosos "têm chegado em seus esforços, os métodos empregados, as dificuldades que tiverem de enfrentar, o que pode ainda ser investigado etc," (p. 100). Neste sentido o autor esclarece que sem um referencial teórico não existe possibilidade de interpretação, explicação e compreensão da realidade.

Neste sentido este artigo intenta interpretar, explicar e compreender o "Lugar da Educação Profissional na Garantia do Direito em um Mundo Comandado pelo Capitalismo Financeiro", E somente por meio da compreensão das contradições do sistema capitalista em sua fase mais avançada: o imperialismo, é possível entender que a resistência é a arma para garantir o direito de acesso e permanência na educação professional.

\section{RESULTADOS E DISCUSSOES}

É de conhecimento público de que na atualidade a Rede Federal de Ensino Profissional oferece a seus estudantes uma educação de qualidade e socialmente referenciada, inclusive ofertando uma Política de Assistência Estudantil que desenvolve vários programas que incluem ações culturais e de saúde preventiva. Todavia, a partir do Governo Temer e com maior 
intensidade no Governo Bolsonaro o capital vem tentando desmontar esta rede e consequentemente ameaçar o direito à educação profissional

É época de resistência contra todo o desmonte que o capital quer implantar e de se reforçar o cuidado com a educação profissional. É período de se intensificar as pesquisas e os estudos para se provar que só quem oferece educação profissional de qualidade pública e gratuita são os Institutos Federais.

Também é indispensável um projeto democrático de educação profissional que assuma uma nova postura frente aos saberes, às práticas de ensinar e de aprender, aos procedimentos de organização curricular e de avaliação. E a construção dessa educação profissional qualitativamente nova perpassa pela sua emancipação em relação ao controle do capital.

Então a palavra do momento é resistência, pois se eles precisam do consenso para destruir completamente com a educação profissional, eles não obterão este consentimento: 1) Porque os movimentos sociais pela educação iram gritar "Tira a mão do meu IF"; 2) Porque os estudiosos da educação profissional irão alertar a população sobre os reais interesses do capital em atacar a educação profissional, por meio de toda produção teórica que vem desenvolvendo. Como no exemplo das ilustrações abaixo:

\section{llustração 1 - Tira a mão do meu IF}

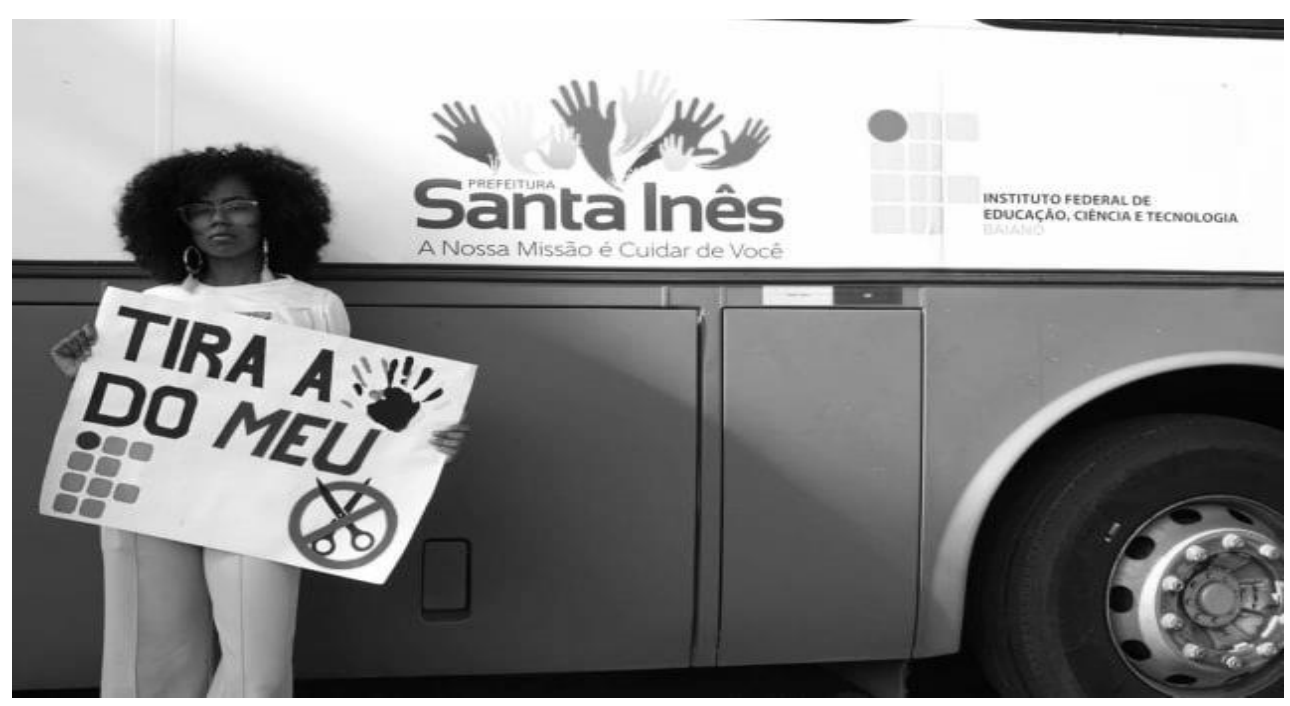

Fonte: Arquivo pessoal Profa Dolores Setuval Assaritti - Mobilização Estudantes IFBaiano Santa Inês: 15/05/2019 


\section{Ilustração 2 - Canal Educação em Pauta - Instituto Federal do Rio Grande do Norte - Programa de Pós- Graduação em Educação Profissional}

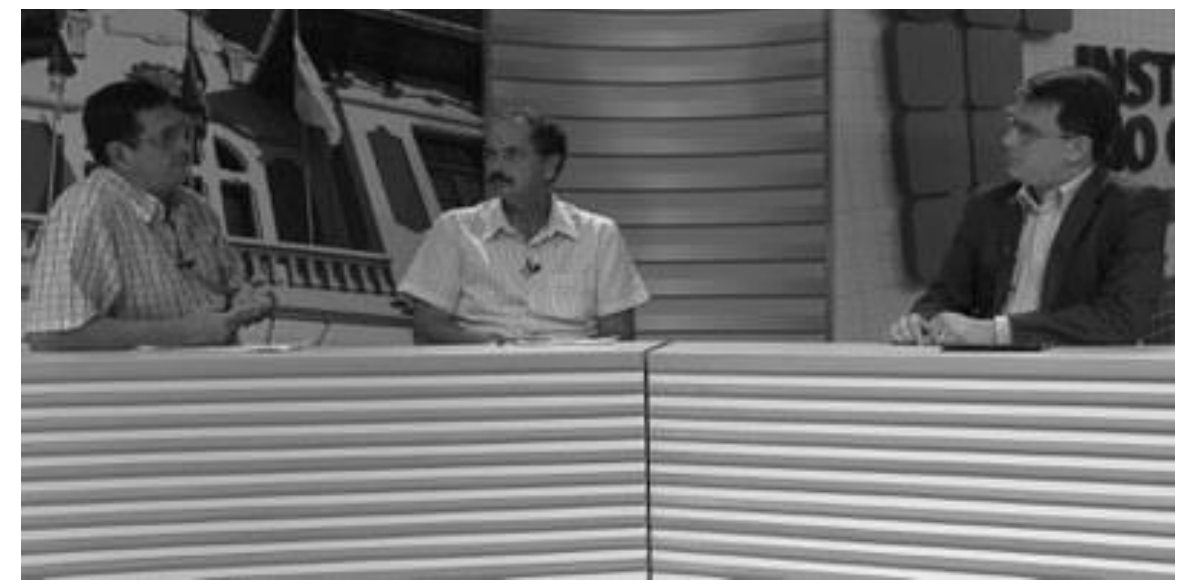

Fonte: Programa Educação em entrevista os professores doutores Dante Moura (IFRN) e Ronaldo Marcos Lima (UFPA) - 14/02/2014

Outra arma de proteção tem sido apontada pela Associação Nacional dos Dirigentes de Instituições Federais de Ensino Superior (ANDIFES) que tem um papel decisivo neste processo de resistência, realizando estudos para comprovar que o Bird manipula informações para prejudicar a oferta de uma educação de qualidade socialmente referenciada.

Se a proposta do Bird, segundo Druck, Filgueira e Moreira (2017) consiste na: 1. Redução dos recursos destinados às Universidades Federais, buscando recursos em outras fontes ou redefinindo sua estrutura de custos; 2.Introdução de tarifas escolares; 3 . Financiamento para estudantes que não puderem pagar as mensalidades; 4 . Bolsas de estudos para os estudantes mais pobres, através do PROUNI.

A contraproposta da educação profissional - amparada em estudos investigativos consistentes da ANDIFES e em pesquisas dos estudiosos da educação com aparato teórico em Marx, Engels e Gramsci - é plantar e cuidar para que cresçam as sementes do ensino de qualidade por meio da correlação de forças que jamais irá permitir o consenso que a hegemonia burguesa precisa para dar seguimento a barbárie contra os Institutos Federais. 


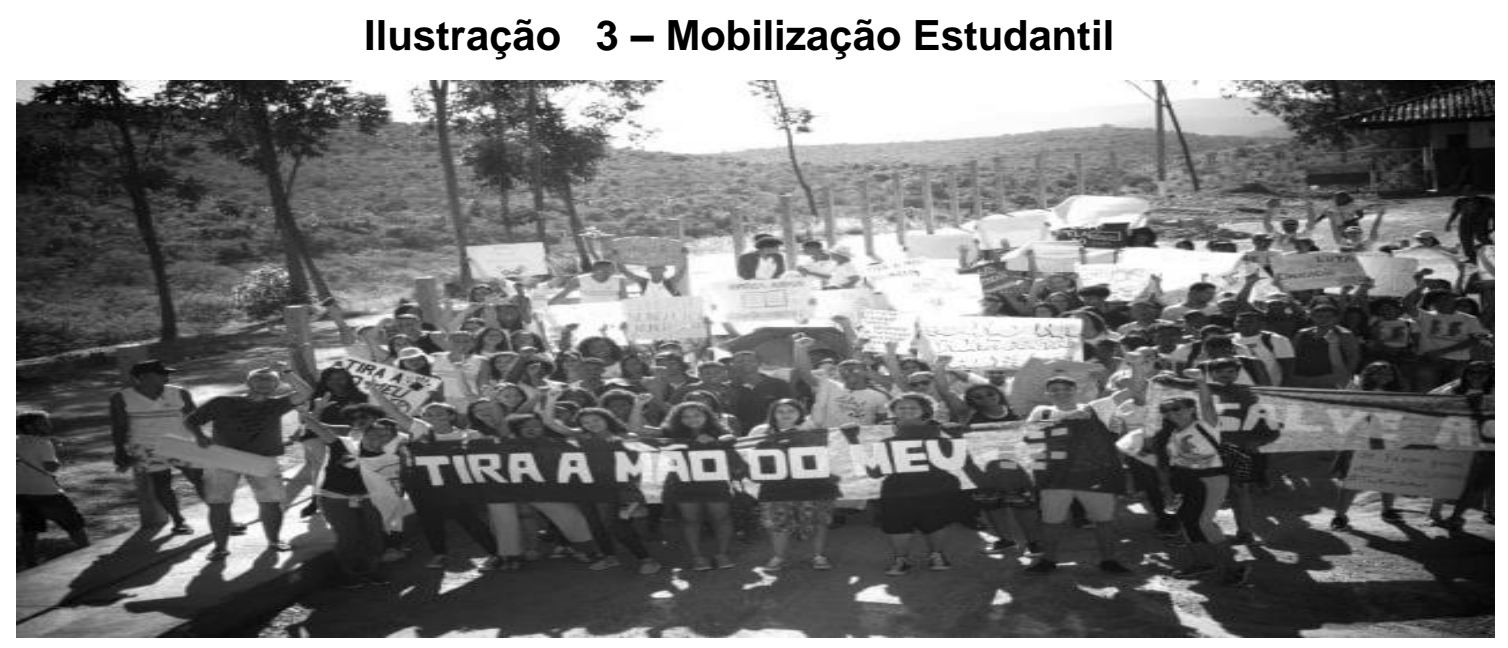

Fonte: Arquivo pessoal Profa Dolores Setuval Assaritti

\section{CONSIDERAÇÕES FINAIS}

É necessário, plantar e cuidar para que cresçam as sementes da formação humana integral, aproveitando-se das contradições do sistema capital. Dante Moura (2013, p. 713).

É momento de plantar e cuidar para garantir o lugar da educação profissional na sociedade capitalista, na Lei de Diretrizes e Bases da Educação e nos Institutos Federais, mesmo em tempos de "Santíssima Trindade do Capital".

Com toda a malignidade que o capital vem dispensando sobre a educação profissional a partir do Governo Temer e sobretudo no Governo Bolsonaro, a frase do momento é "Tira a Mão do meu IF", campanha essa usada pelo movimento estudantil de todo o Brasil e reanimada pelos profissionais que trabalham nas instituições de ensino federais.

Plantar significa reforçar as raízes de uma educação que foi criada para os pobres, mas que jamais se permitiu ser pobre. E cuidar é garantir que a qualidade do ensino profissional permaneça com toda a sua riqueza teórica e prática, não sendo afetada pela malignidade do capital.

O vídeo organizado pelos estudantes do IF Baiano campus Bom Jesus da Lapa (2019) é um exemplo desse plantar e cuidar por parte dos estudantes. Ele está sendo divulgado em todas as redes sociais e é muito emocionante, pois os estudantes mostram, dentre outras coisas, a rotina para chegar até o instituto. Eles acordam 4 horas da manhã, enfrentam estrada de chão para estar na escola às $7 \mathrm{~h}$, estudam em turno integral e passam pela mesma luta para voltar para casa. Tudo isso porque eles acreditam que o IF Baiano oferece uma educação diferenciada e que ninguém pode tirar a mão deste direito!

Diante do exposto, é tempo dos movimentos sociais e dos estudiosos da educação profissional cuidar desta modalidade de ensino tão linda, corroborando para que a sociedade comandada pelo capital não destrua com 
a esperança das pessoas que vivem em situação de vulnerabilidade social de plantar um futuro melhor para seus filhos.

\section{REFERÊNCIAS}

AMÂNCIO FILHO, Antenor. A Formação Profissional de Nível Médio na área da Saúde: A Modalidade Seqüencial em Foco. GTn09 - Trabalho e Educação Introdução. http:fiocruz.br. Acessado em 14/12/2018.

ARAUJO, Ronaldo Marcos de Lima e RODRIGUES, Doriedson do Socorro Rodrigues. Referências sobre Práticas Formativas em Educação Profissional: o velho travestido de novo frente ao efetivamente novo. In: B. Téc. Senac: a E Edu. Prof., Rio de Janeiro, v. 36, n.2, maio/ago. 2010.

BRASIL. Lei no 010172, de 09 de janeiro de 2001. Plano Nacional de Educação. . Lei no 13.005, de 25 de junho de 2014. Plano Nacional de Educação. . Decreto 7.234, de 19 de junho de 2010. Programa Nacional de Assistência Estudantil.

CIAVATTA, Maria. A Formação Integrada: a escola e o trabalho como lugares de memória e de identidade. In: Trabalho Necessário, ano 3, n. 3, 2005.

DAL RI, Maria Neusa e VIEITEZ, Candido Giraldez. Trabalho como Princípio Educativo e Práxis Político-Pedagógica. In: Marx, Gramsci e Vigotski: Aproximações. MENDONÇA, Sueli Guadalupe de Lima, SILVA, Vandei, Pinto da, MILLER, Stela. (orgs). São Paulo: Editores Junqueira\&Marin, 2009. (p. $253-305)$

DEMO, Pedro. A Nova LDB: Ranços e Avanços. 23 ed. Campinas, SP: Papirus, 1997. (Coleção Magistério: Formação e Trabalho Pedagógico)

DRUCK, Graça; Filgueiras, Luiz e MOREIRA, Ualace. Ajuste Fiscal e as Universidades Públicas Brasileiras: A Nova Investida do Banco Mundial. In: Cadernos do CEAS, Salvador/Recife, n. 242, p. 602-634, set/dez, 2017.

FAGNANI, Eduardo. O fim do breve ciclo da cidadania social no Brasil (19882015). In: Texto para Discussão. Unicamp. IE, Campinas, n. 308, jun, 2017, p. 1 a 19. (308)

FRIGOTTO, Gaudêncio. Educação e Trabalho: bases para debater a educação emancipadora. Revista Perspectiva, Florianópolis: EdUFSC, v.19, n. 1 , p.71-87, jan/jun, 2001.

GRUPPI, Luciano. Conceito de Hegemonia em Gramsci. Tradução de Carlos Nelson Coutinho. Rio de Janeiro: Edições Graal, 1978. (Biblioteca Estudos Humanos. Série Teoria Política, n.1). 143 p.

IAMAMOTO, Marilda Vilela. Serviço Social em Tempo de Capital Fetiche: Capital Financeiro, Trabalho e Questão Social. 2. Ed. São Paulo: Cortez, 2008. $495 \mathrm{p}$. 
IFBAIANO CAMPUS BOM JESUS DA LAPA. Documentário Tira a Mão do Meu IF, 2019.

LEITE, Handerson Jorge Dourado. Estrutura Organizacional: base para uma nova arquitetura organizacional do CEFET-BA. 2001. Dissertação (Mestrado em Educação). Instituto Federal de Educação, Ciência e Tecnologia da Bahia - IFBA.

MANFREDI, Silva Maria. Trabalho, Profissão e Escolarização: revisitando conceitos. In: MANFREDI, Silva. Educação Profissional no Brasil. São Paulo: Cortez, 2020. (p. 31 a 61)

MINAYO, Maria Cecília de Souza (Org.). Pesquisa Social. Teoria, método e Criatividade. 23aㅡ ed. Petrópolis: Editora Vozes, 2004. (Coleção Temas Sociais). $80 \mathrm{p}$.

MOURA, Dante Henrique. Ensino Médio Integrado: subsunção aos interesses do capital ou travessia para a formação humana integral? In: Educ. Pesqui., São Paulo, v.39, n.3, p. 705-720, jul./set. .2013

- Educação Básica e Educação Profissional e Tecnológica: dualidade histórica e perspectivas de integração. HOLOS. Natal, V2. P -17, 2007.

PEREIRA, Luiz Augusto Caldas. Desafios da Educação Profissional e Tecnológica. Arquivo formprofisional. Disponível em:

http://chagas.redefiocruz.fiocruz.br/ ensp/biblioteca/dados/formprofissional. pdf. acessado em 22/07/2018.

PINTO, Marina Barbosa. Precarização do Trabalho Docente: Competitividade e fim do Trabalho. In: PEREIRA, Larissa Dahmer e ALMEIDA, Ney Luiz Teixeira de (Org). Serviço Social e Educação. $2^{-}$edição. Ed Lumen Juris / Serviço Social, Rio de Janeiro:2012.

RAMOS, Marise Nogueira. Ensino Médio Integrado: Lutas Históricas e Resistências em Tempos de Regressão. In: Ensino Médio Integrado no Brasil: Fundamentos, Práticas e Desafios. Anais do Seminário Nacional do Ensino Médio Integrado. Publicado em 20/11/2018.

ROSSETTI JÚNIOR, Hélio. Mudanças na história do ensino técnico no Brasil. Disponível em: <http://www.moderna.com.br/escola/prof/art46.htm>. Acessado em 22/07/2018.

SAVIANI, Dermeval. A Nova Lei da Educação: Trajetórias, Limites e Perspectivas. 12ª edição. Campinas: Autores Associados, 2011.

SOUZA, Jacqueline Damiense Almeida de. Na Travessia: Assistência Estudantil na educação Profissional. As interfaces das Políticas de Assistência Social e Educação. 2017, 191p. Dissertação (Mestrado em Política Social). Universidade de Brasília. Departamento de Serviço Social, Brasília.

TRIVIÑOS, Augusto N. S. Introdução à Pesquisa em Ciências: A pesquisa qualitativa em educação. São Paulo: Atlas, 1987. 176 p. 